CERDÀ, Jordi Pere: Cants populars de la Cerdanya i el Rosselló. Edició de Jordi Julià i Pere BALlART. Barcelona: Editorial Mediterrània, 20I6, I8I p.

\title{
Cants populars de Ia Cerdanya i el Rosselló
}

Carme OrIOL CARAzO

Universitat Rovira i Virgili, Tarragona

La literatura popular de la Catalunya del Nord és encara avui molt desconeguda tant per part dels catalans del sud com dels mateixos nord-catalans. A la Catalunya del Nord, com a la resta de territoris de l'àrea lingüística i cultural catalana, hi ha hagut un interès per aquest tipus de literatura des que a mitjan segle xix es va produir el naixement del folklore, i en particular de la literatura popular, com a disciplina científica, objecte d'estudi i de preservació. Aquest interès dels estudiosos nord-catalans s'ha concretat en la publicació de treballs en llibres, revistes i col-leccions, entre d'altres activitats dirigides a la preservació del llegat tradicional. L'any 2017 la investigadora i professora de la Universitat de Perpinyà Martine Berthelot va publicar la part dedicada a la Catalunya del Nord dins de l'obra col-lectiva Història de la literatura popular catalana, editada a cura de Carme Oriol i Emili Samper. ${ }^{I}$ El treball de Berthelot, rigorós i aprofundit, posa en valor la tasca dels estudiosos nord-catalans en la salvaguarda de la literatura popular catalana i aporta moltes dades sobre els autors i les obres que en cadascun del períodes analitzats van deixar la seva petjada. Així, Berthelot ens parla d'una Renaixença rossellonesa en la qual es van interessar per la recuperació de la literatura popular homes com Justí Pepratx (I828-I90I) i Pere Courtais (I8I6-I888), que van estar en contacte amb erudits i folkloristes de Catalunya. Així, per exemple, Pepratx va rebre l'estímul de Jacint Verdaguer mentre que Courtais va ser corresponsal de Manuel Milà i Fontanals. També destaquen homes com Josep Bergnes (I8I5-I885), Josep Bonafont (I854-I935), Carles Bosch de la Trinxeria (I83I-I897) i sobretot l'arxivista Pere Vidal (I848-I929), considerat el pioner en la recopilació i publicació del folklore rossellonès. En una segona etapa, que es va iniciar a principi del segle xx, hi destaquen noms com el de Joan Amade (I878-I949), Esteve Caseponce (I850-I93I), Horaci Chauvet (I873-I962), Carles Grandó (I889-I975), Charles Bauby (I898-I97I) i Pierre Fouché (I89I-I967), entre d'altres. Dins d'aquest grup d'intel-lectuals, mereixen un comentari especial l'escriptor Josep Sebastià Pons i la seva germana, la poetessa Simona Gay. Tots dos van realitzar una interessant arreplega de materials de literatura popular, el primer amb una finalitat literària, ja que se'n va servir per a la seva obra de creació, i la segona amb una intenció etnogràfica. En una tercera etapa, hi van tenir un paper fonamental l'escriptor Jordi Pere Cerdà, pseudònim d'Antoni Cayrol (I920-2OII), que va recollir rondalles, llegendes i cançons, així com altres autors entre els quals cal esmentar Edmon Brazès (I893-I980) i Enric Guiter (I909-I994).

En aquest breu recorregut sobre l'aportació dels autors nord-catalans a la recol-lecció i l'estudi de la literatura popular, cal aturar-se ara en la figura de Jordi Pere Cerdà, autor del recull que és el motiu de la present ressenya, Cants populars

I Història de la literatura popular catalana. A cura de Carme Oriol i Emili Samper. Alacant / Palma/Tarragona: Publicacions Universitat d'Alacant/Edicions Universitat de les Illes Balears / Publicacions Universitat Rovira i Virgili, 2017. 
de la Cerdanya i el Rosselló, publicat el desembre de 2016 a cura dels professors de la Universitat Autònoma de Barcelona Jordi Julià i Pere Ballart.

Jordi Pere Cerdà, l'escriptor de Sallagosa, com sovint se'l coneix pel fet d'haver nascut i viscut bona part de la seva vida en aquesta població de l'Alta Cerdanya, va conrear gèneres com el teatre, la poesia, la novel-la, l'assaig i l'autobiografia. Autor d'una important obra literària, va ser guardonat amb el Premi de la Crítica Serra d'Or (I985), el Premi de Literatura de la Generalitat de Catalunya (I989), la Creu de Sant Jordi (I986), el Premi d'Honor de les Lletres Catalanes (I995), el Premi Nacional de Literatura (I999) i el Premi Méditerranée Roussillon (2007). Però a més de la seva vessant creadora, que li ha valgut un merescut reconeixement, és important destacar una altra vessant seva per la qual és menys conegut: la de recopilador, estudiós i divulgador de la literatura popular nord-catalana.

En el terreny de la literatura popular, Jordi Pere Cerdà és autor del llibre Contalles de Cerdanya, un recull de dotze relats que ha conegut diverses edicions, i que en la darrera de 200I, ${ }^{2}$ amb la incorporació d'un relat nou, augmenta el total fins a tretze. Sobre la motivació i la forma d'escriure les rondalles, és important conèixer el testimoni d'Albert Manent en la presentació de l'edició de I96I, que Berthelot, en l'estudi citat anteriorment, presenta de la següent manera: «Quan ja era ben conegut com a poeta, l'any I958 publicà Contalles de Cerdanya en resposta al repte d'escriure prosa que havia proposat l'escriptor Albert Manent als literats rossellonesos a través de la revista Tramontane. Sense poder, però, restituir en brut les contalles que havia recollit de viva veu, va enriquir les que eren només una anècdota, tot i que en conservava el nucli original i la forma popular, i es recolzava probablement en les obres de Caseponce pel que feia al llenguatge folklòric».3 Així, en la dècada dels anys cinquanta del segle xx, Jordi Pere Cerdà va utilitzar uns relats procedents de la tradició oral per publicar prosa en català, literaturitzant aquests relats, amb una motivació i una manera de fer semblant a la que van seguir altres escriptors catalans, com per exemple Enric Valor al País Valencià. Valor va escriure els 36 relats que configuren el recull Rondalles valencianes (I95O, I95I), a proposta de Manuel Sanchis Guarner; en el seu cas, però, com una forma d'escriure literatura en llengua catalana quan la censura li va prohibir publicar la novel.la L'ambició d'Aleix.

Contalles de Cerdanya ha estat fins ara l'únic recull en forma de llibre que ha permès conèixer la tasca duta a terme per Jordi Pere Cerdà com a folklorista, és a dir, com a recopilador i estudiós d'uns relats que formen part del patrimoni oral de la seva comarca, l'Alta Cerdanya.

Amb la publicació del llibre Cants populars de la Cerdanya i el Rosselló, podem conèixer l'activitat d'arreplega i d'estudi de Jordi Pere Cerdà en un altre dels grans gèneres de la literatura popular: el cançoner. El llibre que ara ens ocupa no és exclusivament un recull de cançons, és a dir, un recull fet només amb la intenció de donar a conèixer els textos d'unes cançons recollides de la tradició oral, sinó que és un treball molt més complet, ja que conté uns textos previs que fan de coixí al cançoner pròpiament dit en tant que expliquen molts aspectes contextuals i

\footnotetext{
2 La dona d'aigua de Lanós. Contalles de Cerdanya. Canet: Trabucaire, 200 .

3 Martine Bertelhot: «Catalunya del Nord». Dins Història de la literatura popular catalana. A cura de Carme Oriol i Emili Samper. Alacant / Palma / Tarragona: Publicacions Universitat d'Alacant / Edicions Universitat de les Illes Balears / Publicacions Universitat Rovira i Virgili, 2017, p. 528.
} 
complementaris que enriqueixen extraordinàriament la part dedicada a la difusió dels textos de les cançons.

El llibre comença amb una «Presentació», signada per l'Associació Jordi Pere Cerdà, que ens ajuda a situar-nos en el context que ha fet possible l'edició del llibre, i on s'hi fa constar l'agraïment a aquelles persones i institucions que hi han participat. Aquesta darrera dada és important perquè el llibre es publica a títol pòstum, després d'uns esforços fets en vida de l'autor que no van arribar a donar fruits. A continuació, hi trobem l'estudi «Rituals del plaer d'ésser», a càrrec de Jean-Baptiste Para, redactor en cap de la revista Europe. En el seu text, l'autor relaciona l'interès de Jordi Pere Cerdà per les cançons populars amb la seva condició de poeta i parla del que va significar per a l'autor endinsar-se en el món de la cançó popular. Així, per exemple, recollint les paraules que va escriure el mateix Jordi Pere Cerdà, destaca la utilitat del recull en el sentit que la cançó popular pot ser una font d'interès per al sociòleg, l'historiador, el lingüista i el musicòleg. Finalment, explica que per a Jordi Pere Cerdà la cançó popular era l'ànima del poble, en tant que s'hi troben temes com: el joc amorós, la complanta de les dones casades, l'evocació de la condició difícil dels pastors i l'empremta dels esdeveniments històrics i les lluites socials (p. I7). Amb aquestes paraules, Jean-Baptiste Para posa el lector en situació del que trobarà després, l'anàlisi, amb voluntat interpretativa, de Jordi Pere Cerdà sobre el sentit de la cançó popular. Un tercer text, «Jordi Pere Cerdà i la cançó popular», escrit per Jordi Julià, comença explicant com es va gestar la publicació del recull. Concretament va ser l'any 2009, en una conversa a Sallagosa amb l'autor i la seva esposa Helena. Fruit d'aquesta trobada, i a la vista de l'important material conservat, però també gràcies a la voluntat expressa de Jordi Pere Cerdà perquè les cançons poguessin ser publicades, es van posar tots els mitjans possibles per aconseguir-ho. En aquest text, Julià explica aspectes de gran interès relacionats amb la confecció del recull com ara: l'inici de la recollida de les cançons cap als anys quaranta del segle xx, la continuació de l'arreplega als anys seixanta, l'afició a la música de Jordi Pere Cerdà, la interpretació i l'enregistrament d'algunes de les cançons per part del mateix recol-lector, la impossibilitat de publicar el cançoner tot i els diversos intents de l'autor per aconseguir-ho o els comentaris sobre els informants. Entre els diversos aspectes analitzats per Julià, destaca el de l'interès de Jordi Pere Cerdà per les formes lingüístiques contingudes en la cançó popular, ja que aquest coneixement li podia permetre enriquir la seva llengua literària, una finalitat que també va motivar el seu treball rondallístic. En aquest sentit, Julià posa sobre la taula el tema de l'estil literari de l'escriptor i de la influència de la literatura popular en la literatura culta, i comenta que caldria abordar-lo per entendre i interpretar millor l'obra de l'escriptor: «cal escriure encara l'estudi que ens mostri com aquests cants tradicionals van influir la forma de concebre els seus poemes, i com van proporcionar-li un lèxic que coneixia però que, sens dubte, no estava habituat a fer servir per escriure, ni tampoc a donar-li un ús estètic» (p. 30-3I). En darrer lloc, «Els criteris d'edició», a càrrec de Pere Ballart, precedeixen el cançoner pròpiament dit. A través d'aquest escrit, sintètic i clar, sabem quina ha estat la tasca dels editors davant de les dificultats amb què s'han trobat per publicar «un original que presentava un estat de composició i de redacció gairebé definitiu, però encara amb molts detalls inclonclusos» (p. 33). En resum, es pot dir que el criteri adoptat ha estat respectar al màxim l'original, i intervenir-hi només quan ha estat estrictament necessari i amb la clara voluntat 
d'orientar el lector amb notes explicatives «sempre amb la intenció d'informar sobre la història, els personatges i els referents autòctons de la regió rossellonesa o bé sobre aquells materials, que pertanyent al corpus literari del mateix Jordi Pere Cerdà, podien completar les dades i les impressions que el poeta havia emès sobre el material recopilat» (p. 34).

El cançoner pròpiament dit, «Cants populars de la Cerdanya i el Rosselló», està format per l'estudi de Jordi Pere Cerdà, «La vida dels pastors segons la cançó popular», el treball «Estudi i presentació dels cants», que l'autor va elaborar com a introducció al cançoner, i «Les lletres de les cançons», que són els textos dels cants que configuren el cançoner. Tots aquests treballs donen al cançoner un caràcter de recull folklòric modern, elaborat amb criteri científic, en tant que s'hi observa un rigor, una metodologia i una voluntat d'analitzar i d'interpretar uns materials recollits de la tradició oral. També ens mostren l'agudesa, la intuïció i el saber fer de Jordi Pere Cerdà en aquesta vessant seva tan poc coneguda de folklorista.

«La vida dels pastors segons la cançó popular» és un text que no formava part del cançoner tal com va ser concebut per l'autor, però que els editors, Jordi Julià i Pere Ballart, van pensar que calia incloure en aquesta publicació, ja que té una relació molt directa amb el contingut del cançoner. Es tracta del text de la conferència que Jordi Pere Cerdà va fer el I96I, i que finalment es va publicar el I986 al volum Aspects de la Cerdagne, editat a Perpinyà per la Société Agricole, Scientifique et Littéraire. En aquest treball, l'autor reivindica l'interès de la cançó popular i esmenta alguns dels autors i dels reculls més importants que hi ha hagut fins ara, com per exemple els de Manuel Milà i Fontanals i l'Obra del Cançoner Popular de Catalunya. Materials, a Catalunya, i els de Pere Vidal i Carles Grandó, al Rosselló. Tot seguit, se centra en la importància que té la cançó en la vida dels pastors i també en les cançons que els tenen com a protagonistes. En la seva exposició il-lustra els comentaris amb textos de cançons, amb la qual cosa s'aconsegueix com a resultat un discurs molt amè i didàctic. Entre els temes de les cançons trobem, per exemple, el de la malcasada, que apareix en cançons tan conegudes com «Muntanyes regalades» $\mathrm{O}$ «Rossinyol, si vas a França». Amb relació a aquest tema, és de destacar l'anàlisi interpretativa de Jordi Pere Cerdà en el sentit que, a través de la cançó popular, es podia exercir una crítica cap a situacions injustes que patien les dones. Per exemple, les dones no podien triar marit, però en alguns casos la cançó popular permet expressar una certa revenja cap a aquesta situació. Els comentaris de Jordi Pere Cerdà sobre les cançons no es redueixen a aspectes de contingut, sinó que sovint s'observa l'interès per destacar frases i expressions lingüístiques que li criden l'atenció per la seva bellesa i capacitat de resumir sentiments i emocions. La conferència, ben documentada, amb al-lusions a versions recollides per altres folkloristes, inclou reflexions sobre l'origen de determinades versions, la música amb què s'interpreten, la relació amb cançons occitanes i, fins i tot, el record d'anècdotes personals.

El següent text, «Estudi i presentació dels cants», és el que va elaborar Jordi Pere Cerdà com a introducció al llibre que recollia les cançons. En aquest estudi, l'autor explica que el llibre és el resultat de quinze anys d'arreplega. A més, comenta que ha confrontat les seves cançons amb les dels cançoners Folklore de Catalunya: Cançoner (I95I), de Joan Amades; Romancerillo catalán (I992), de Manuel Milà i Fontanals, i El cançoner del Calic (I9I3), de Joan Serra i Vilaró, i, fruit d'aquesta confrontació, fa el següent comentari sobre els inèdits: «Són poques les 
que puc presentar com a inèdites al complet. En el terreny musical, al contrari, les versions que reporto són quasi totes diferents, algunes simplement variants o més boniques» (p. 73). Jordi Pere Cerdà també fa un esment dels autors que l'han precedit en l'arreplega de cançons populars a la Catalunya del Nord. Diu: «Abans d'aqueixa arreplega són tres, al meu coneixement, els que s'han dedicat d'aqueixa banda de frontera a una recerca volguda i metòdica de cants populars: en Pere Vidal i els senyors Vilarem i Carcassonne» (p. 87-88). Sobre els aspectes musicals als quals al-ludeix Jordi Pere Cerdà en el seu comentari sobre els inèdits, cal dir que aquests són objecte d'atenció per part de l'autor. Tot i això, el recull presenta només els textos, sense la corresponent notació musical. Aquesta mancança queda compensada, en bona part, per l'extensa selecció de cançons (un total de quaranta-quatre) que formen part dels dos CD que conté la present edició del llibre. Les cançons, interpretades per Jordi Pere Cerdà, constitueixen la meitat de les que s'han transcrit al llibre, que són vuitanta-vuit.

El text «Estudi i presentació dels cants» conté també la presentació dels informants. Per a cadascun d'ells, un total de tretze (nou dones i quatre homes), l'autor dona les dades biogràfiques bàsiques (edat, lloc de residència, ofici, parentiu), n'adjunta una imatge fotogràfica, i completa aquestes breus biografies amb anècdotes i comentaris diversos que ajuden a copsar detalls de la personalitat dels informants. Després d'aquesta breu presentació dels informants, es detallen els títols de les cançons, es fa referència a altres versions contingudes en els cançoners amb què l'autor ha fet la confrontació de les cançons i es destaca, per tant, quines de les cançons aplegades no apareixen en aquests cançoners. Jordi Pere Cerdà explica el perquè de presentar cada informant amb el seu repertori. Ens diu que, en perdre's la funció, les cançons van quedar relegades a l'àmbit familiar, per la qual cosa, a cada casa es coneix un petit repertori de cançons que es transmet entre els membres de la família. Per això, no s'han classificat per gènere (d'acord amb la funció que tenien) com fa Amades. Tot i que en aquesta presentació es dona la informació sobre tretze informants, l'autor comenta que el total de cantaires ha estat de divuit (tretze dones i cinc homes) (p. 74-75). Sobre aquesta qüestió, els editors del llibre expliquen: «cal suposar que idealment ell va projectar que faria el mateix amb tots els cantants i totes les cançons que li van proporcionar, els quals són més dels que va tenir temps d'anar glossant, si parem atenció als fulls que va deixar escrits i on va anar registrant la identitat i la procedència de totes les persones amb qui es va posar en contacte perquè li interpretessin algun cant popular» (p. II5). A continuació, els editors, reprodueixen aquestes llistes, «malgrat el seu caràcter incomplet, la seva possible imprecisió o el fet que fos més un document de treball d'ús personal que no pas un material de consulta definitiu» (p. II3).

Després de l'estudi introductori, la darrera part del llibre inclou «Les lletres de les cançons». En aquesta part es presenten les cançons ordenades per ordre alfabètic del títol i amb anotacions dels editors. Aquestes notes inclouen aspectes com: variants en la lletra i la música, referències a versions d'altres cançoners o discrepàncies entre algunes de les versions publicades i les cantades per Jordi Pere Cerdà (que es presenten incloses en els CD que acompanyen la publicació). Els editors també han tingut cura de presentar unes imatges representatives de la documentació utilitzada per a l'edició del llibre com, per exemple, algunes partitures provinents del fons de l'autor. Pel que fa a les cançons aplegades, el llibre conté cançons força conegudes també en altres llocs, com per exemple «A la vora 
de la mar», «Cançó del lladre», «El testament d'Amèlia», «La dida» i «Sant Josep fa bugada», en versions relativament extenses que presenten la seva particular fesomia; també conté altres cançons menys desenvolupades, que de vegades són fragments de cançons prou conegudes, com «La noble dama» o «Déu vos guard Josep». Pel que fa a la seva funcionalitat, s'identifiquen, per exemple, algunes cançons de Nadal que són conegudes també en altres territoris. En alguns casos, determinats elements del text poden donar indicis sobre el seu ús. Per exemple, la primera versió de «La dida» (de les dues que inclou el cançoner) conté la tornada «La non-non, fem-li non-non, / diu que si la dida canta / l'infant dorm», que fa pensar en una cançó de bressol; les tres estrofes de «L'herba revenial» corresponen a les fórmules internes d'una rondalla molt coneguda internacionalment, de la qual en la tradició catalana en tenim documentades trenta versions a la base de dades RondCat. Cercador de la rondalla catalana ${ }^{4}$ sota el tipus rondallístic ATU 780 i amb el títol «La flor de panical»; i «Partida de cartes» fa pensar en una cançó per acompanyar un joc de cartes, tal com indica el mateix títol i les moltes referències en el text sobre el nom de les cartes i la idea de joc. En definitiva, el cançoner presenta un repertori molt interessant que pot obrir moltes reflexions i vies d'estudi a part de les ja apuntades per l'autor i pels editors. El llibre Cants populars de la Cerdanya i el Rosselló constitueix, doncs, una important aportació per a l'estudi de la literatura popular catalana. És un testimoni d'una època i, sobretot, d'una gent que ha conservat en la memòria una part d'un saber tradicional que ens enriqueix com a cultura. Però, a més, és també el testimoni que ens ha deixat Jordi Pere Cerdà, un dels autors nord-catalans més reconeguts, a través de la transcripció i la interpretació personal (amb la seva pròpia veu) d'unes cançons delicioses.

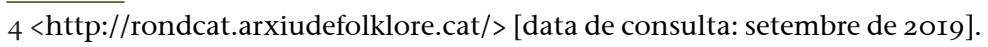

